\title{
Pemberdayaan Kelompok Ibu Rumah Tangga Melalui Pembentukan Home Industry Sabun Pencuci Lantai Berbahan Dasar Limbah Minyak Jelantah
}

\author{
Sumiati ${ }^{1}$, Tb. Ai Munandar ${ }^{2}$ Arifina Febriasari ${ }^{3} \operatorname{Suryaman}^{4}$ Sulasno $^{4}$ \\ Apriliana Dwijayanti ${ }^{6}$ \\ ${ }^{1,2}$ Program Studi Teknik Informatika, Fakultas Teknologi Informasi, Universitas Serang Raya \\ ${ }^{3,6}$ Program Studi Teknik Kimia, Fakultas Teknik, Universitas Serang Raya \\ ${ }^{4}$ Program Studi Ekonomi , Fakultas Ekonomi dan Bisnis, Universitas Serang Raya \\ ${ }^{5}$ Program Studi Hukum, Fakultas Ilmu Sosial dan Politik, Universitas Serang Raya \\ Email: sumiati82@yahoo.com ${ }^{1}$; tbaimunandar@gmail.com² arifinafebriasari1725@gmail.com $^{3}$; \\ apriliana.d@gmail.com ${ }^{6}$
}

\begin{abstract}
Abstrak
Minyak goreng merupakan kebutuhan sehari sehari yang digunakan oleh ibu rumah tangga untuk keperluan memasak, namun masyarakat belum menyadari bahwa minyak goreng yang sudah tidak digunakan dapat dimanfaatkan menjadi produk rumah tangga, dimana jumlah minyak jelantah (minyak bekas) tanpa disadari jumlah melimpah, sehingga dengan permasalahan yang ada, maka minyak jelantah tersebut dapat berubah pemanfaatan menjadi sabun pencuci lantai berbahan dasar limbah minyak jelantah. Banyak minyak Jelantah (minyak bekas) tidak digunakan atas pemanfaatan yang ada, sehingga dapat memanfaatkan limbah minyak jelantah tersebut menjadi produk rumah tangga seperti sabun pencuci lantai. Disatu sisi, pada umumnya masyarakat belum produktif secara ekonomi,sulit menumbuhkan jiwa berwirausaha untuk menciptakan lapangan pekerjaan. Pada umumnya masyarakat masih beranggapan bahwa bekerja pada suatu perusahaan merupakan hal yang sangat luar biasa, sehingga dengan paradigma masyarakat beranggapan bekerja disuatu perusahaan, merupakan suatu hal yang luar biasa, maka banyak sekali terjadi penggangguran. Tanpa disadari dampak dari pengangguran sangat terasa, dimana banyak terjadi tindakan kriminal yang terjadi pada lingkungan, sehingga untuk mengatasi hal tersebut, dilakukan seperti pemberdayaan masyarakat untuk kemanadiran perekonomian masyarakat berbasis pelatihan, pelatihan pelatihan itu dilakukan proses mendeversifikasi minyak jelantah menjadi produk rumah tangga, seperti superpell. Sehingga dengan pelatihan pelatihan yang diberikan ke masyarakat diharapkan masyarakat dapat lebih produktif secara ekonomi meliputi segi produksi dan manajemen usaha, selain itu dapat membantu menciptakan ketentraman, dan kenyamanan dalam kehidupan masyarakat dan dapat meningkatkan keterampilan berpikir sofskill dan hardskill, metode yang akan digunakan dalam pencapaian tujuan tersebut dengan memberikan pelatihan pendidikan kewirausahaan, mendorong home industri, dan membantu dalam hal pemasaran produk . Sehingga dapat meningkatkan taraf hidup masyarakat dan dapat meciptakan lapangan pekerjaan, sehingga kehidupan masyarakat menjadi lebih baik.
\end{abstract}

Kata Kunci: Kemandirian Ekonomi Masyarakat Desa, kewirausahaan, limbah minyak jelantah, produk rumah tangga,pencuci lantai.

\begin{abstract}
Cooking oil is a daily requirement that is used by housewives for cooking purposes, but the public does not realize that cooking oil that has not been used can be used as a household product, where the amount of used oil (used oil) is unwittingly abundant, so with problems that is, the used cooking oil can be transformed into floor washing soap based on waste cooking oil waste. A lot of used oil (used oil) is not used for existing uses, so that it can be used as household products such as floor washing soap. On the one hand, in general the community has not been economically productive, it is difficult to grow the spirit of entrepreneurship to create jobs. In general, the community still thinks that working for a company is a very extraordinary thing, so that with the paradigm of the community assuming that working in a company is an extraordinary thing, there is a lot of unemployment. Unwittingly the impact of unemployment is felt, where there are many criminal acts that occur in the environment, so to overcome this, carried out like community empowerment for the presence of a community-based training economy, trainings is carried out to de-process waste cooking oil into household products, like brand Superpell . So that with trainings given to the community it is hoped that the community can be more economically productive including the aspects of business production and management, besides that it can help create peace and comfort in people's lives and can improve soft skills and skills, the methods to be used to achieve goals by providing entrepreneurship education training, encouraging home industries, and assisting in product marketing. So that it can improve people's lives and create jobs, so that people's lives get better.
\end{abstract}

Keywords: Economic Independence of the Village Community, entrepreneurship, waste cooking oil, household products, solid soap, room deodorizer. 


\section{PENDAHULUAN}

Kebutuhan ibu rumah tangga dalam proses mengolah makanan mentah menjadi makanan matang, memerlukan bahan pendukung seperti minyak goreng, margarin, namun pada umumnya masyarakat dalam proses menggoreng makanan menggunakan minyak goreng. Pemakaian minyak goreng yang sangat berlimpah, menyebabkan minyak goreng bekas (minyak jelantah) semakin banyak, namun kesadaran masyarakat masih minim sekali bahaya penggunaan minyak jelantah untuk menggoreng kembali, selain itu sisa dari minyak jelantah dalam jumlah besar dimana masyarakat sering membuang sisa minyak bekas dibuang hanya ditempat cucian piring saja, sehingga dengan tindakan tersebut akan mencemari lingkungan yang tidak bersih. Permasalahan tesebut dapat diatasi untuk mengurangi pencemaran lingkungan, kita melakukan mendeversifikasikan minyak jelantah tersebut menjadi produk rumah tangga seperti, sabun pencuci lantai berbahan dasar limbah minyak jelantah.

Permasalahan yang dihadapi masyarakat karena awamnya pengetahuan mendeversifikasikan minyak jelantah menjadi suatu barang yang bermanfaat, sehingga pendapatan masyarakat didesa tersebut masih dibawa minim rata-rata, dengan diadakan pelatihan ini diharapkan bahwa masyarakat tidak hanya berfikir sebagai tenaga kerja yang bekerja di suatu perusahaan, namun mereka membuka paradigma untuk membuka lapangan pekerjaan, sehingga secara otomatis pendapatan masyarakat didesa tersebut akan meningkat. Selain itu setelah diadakan pelatihan diversifikasi minyak jelantah menjadi produk rumah tangga, sehingga banyak minyak jelantah (minyak bekas) yang sudah tidak terpakai atas pemanfaatannya dan dapat memanfaatkan dari limbah minyak jelantah tersebut menjadi superpell. Disatu sisi, masyarakat belum produktif secara ekonomis, dan sulit menumbuhkan jiwa berwirausaha untuk menciptakan lapangan pekerjaan. Bekerja pada suatu perusahaan, masyarakat masih banyak menganggap merupakan hal yang sangat luar biasa, karena masyarakat belum memiliki modal usaha baik secara mental maupun modal. Sehingga dari paradigma tersebut banyak terjadi pengangguran, dampak dari pengangguran banyak tindakan kriminal yang terjadi dilingkungan. Ketersediaan sumber daya manusia dapat memanfaatkan untuk membentuk unit unit usaha baru untuk membentuk dan mengembangkan sekelompok masyarakat yang mandiri secara ekonomi didesa tersebut.
Tujuan dari pengabdian masyarakat ini adalah pemberdayaan masyarakat untuk kemandirian perekonomian desa melalui pemanfaatan limbah minyak jelantah menjadi produk rumah tangga seperti superpell (Pembersih lantai). Sehingga masyarakat dapat produktif secara ekonomi meliputi segi produksi dan manajemen usaha, selain itu dapat membantu menciptakan ketentraman, dan kenyamanan dalam kehidupan masyarakat dan dapat meningkatkan keterampilan berpikir sofskill dan hardskill, dengan memberikan pelatihan pendidikan kewirausahaan, mendorong home industri, dan membantu dalam hal pemasaran produk. Sehingga target dari kegiatan pengabdian ini meningkatkan taraf hidup masyarakat dan dapat meciptakan lapangan pekerjaan, sehingga masyarakat mandiri secara ekonomi.

\section{METODOLOGI PENGABDIAN}

Kegiatan Pelatihan Pemberdayaan Kelompok Ibu Rumah Tangga Melalui Pembentukan Home Industry Sabun Pencuci Lantai Berbahan Dasar Limbah Minyak Jelantah di desa Taktakanyang dilaksanakan adalah metode penyuluhan langsung, yaitu penyuluhan dilakukan dengan cara bertatap muka sewcara langsung antara pemateri dan masyarakat, dan melakukan proses diskusi dengan masyarakat.

\section{PELAKSANAAN PENGABDIAN KEPADA MASYARAKAT}

\section{Tahapan-tahapan yang ditempuh untuk melaksanakan solusi atas permasalahan yang dihadapi oleh mitra .}

Tahapan-tahapan yang ditempuh untuk melaksanakan solusi atas permasalahan yang dihadapi oleh mitra sebagai berikut:Observasi awal lokasi untuk mengetahui permasalahan yang dihadapi oleh mitra dan mengidentifikasi program-program yang akan dilaksanakan untuk menyelesaikanmasalah tersebut, mempersiapkan materi baik untuk materi,program kerja awal sampai kegiatan terlaksana untuk mencapai solusi yang dihadapi oleh mitra, mempersiapkan bahan-bahan dan peralatan untuk pemanfaatan limbah minyak jelantah menjadi produk rumah tangga seperti sabun pada, pewangiruangan dan pembentukankelompok-kelompokPemberdayaan masyarakat untuk menunjang pelatihan, mengadakan 
pelatihan bagi masyarakat mengenai kewirausahaan, memberikan pelatihan mengenai pengurusan ijin mengenai cara mendaftarkan hasil produksi dan sampai proses pemasaran hasil produk, melakukan Pelatihan Pelatihan Pemberdayaan masyarakat untuk kemandirian perekonomia desa melalui pemanfaatan limbah minyak jelantah menjadi Superpell, menguji hasil Pemanfaatan limbah minyak jelantah menjadi superpell di laboratorium untuk uji kelayakan, membuat gerai produk yang dihasilkan oleh setiap kelompok usaha,membantu proses pemasaran serta memberikan pelatihan starategi pemasaran produk, mengevaluasi hasil produk karya kelompok masyarakat.

\section{Metode Pendekatan yang ditawarkan menyelesaikan persoalan mitra .}

Metode pendekatan yang ditawarkan untuk menyelsaikan persoalan mitra sebagai berikut: Pemberdayaan masyarakat untuk kemandirian perekonomian desa dengan membentuk kelompokkelompok usaha masyarakat, membentuk unit unit usaha dengan tujuan dibentuknya unit unit usaha kecil adalah masyarakat dapat belajar menguasai keterampilan dengan baik dan memiliki skill maupun hardskill.

Pendidikan Kewirausahaan masyarakat dengan melakukan kegiatan keterampilan yang bertujuan untuk membuka usaha kecil sehingga masyarakat dapat membuka peluang pekerjaan yang dapat memberi nilai tambah dari produk yang dihasilkan oleh desa tersebut. Pendidikan kewirausahaan masyarakat bertujuan untuk membentuk dan mengembangkan kelompok-kelompok agar memiliki keterampilan khusus untuk meningkatkan pengetahuan dalam berwirausaha.Kegiatanpendidikankewirausahaan ini akan terbentuknya usahawan-usahawan baru. Kegiatan Pendidikan kewirausahaan masyarakat ini difokuskan pembentukan unit- unit usaha kelompok masyarakat yang di pemberdayakan meliputi,home industri mengenai hasil limbah minyak jelantah menjadi superpell (Pembersih lantai), memberikan pelatihan mengenai pengurusan ijin mengenai cara mendaftarkan hasil produksi dan sampai proses pemasaran hasil produk.

\section{Tahap-tahapan Pelatihan Pembuatan Limbah Minyak Jelantah menjadi Superpell (Pembersih Lantai)}

Limbah Minyak Jelantah agar dapat dijadikan Superpell (Pembersih lantai) yang ramah lingkungan perlu melalui beberapa proses, adapun proses yang dilakukan dalam pembuatan Minyak Jelantah Menjadi Superpell (Pembersih lantai) adalah sebagai berikut, kumpulkan semua limbah minyak jelantah didalam tempat campurkan semua minyak jelantah dengan ampas tebu, rendam Ampas tebu didalam minyak jelantah selama 2 hari, pisahkan ampas tebu dengan minyak jelantah/disaring yang sudah direndam, Serut lilin yang sudah disiapkan, Siapkan bahan pewarna makanan,lilin yang sudah diserut , jelly powder dan Natrasol Panaskan semua bahan bahan tersebut beserta minyak jelantah, masukan hasil adonan tersebut ke dalam cetakan, diamkan selama 1 hari pembersih lantai yang sudah dicetak, kemas Pembersih lantai untuk siap dipasarkan.

\section{HASIL DAN PEMBAHASAN}

Berikut adalah hasil kegiatan pengabdian yang sudah dilaksanakan sesuai dengan program kerja yang telah disusun sebelumnya. Proses mendeversifikan minyak jelantah menjadi superpel sebagai berikut: minyak jelantah direndam dengan ampas tebu selama satu malam, setelah minyak jelantah direndam dengan ampas tebu, dilakukan proses penyaringan minyak jelantah tersebut dicampur dengan arpus dan $\mathrm{KOH}$, kemudian langkah selanjutnya ditambahkan dengan asam sitrat dan teksapon dicapur secara merata dan kemudian diendapkan satu malam, setelah hasil endapan satu malam hasil akhirnya ditambahkan dengan pewangi dan CMC.

Kampung Parumasan merupakan desa yang memiliki potensi dalam hal kekayaan alam, salah satunya yaitu buah melinjo. Setiap rumah rata-rata memproduksi melinjo untuk dijadikan produk olahan emping/ceplis. Hal ini menjadi fokus dasar untuk berinovasi menjadikan melinjo sebagai olahan yang berbeda. Memanfaatkan kesempatan ini untuk menciptakan produk unik berupa "Kurma Coklat Isi Biskuit Melinjo" yang dapat dimanfaatkan oleh ibu ibu sekitar Kp. Parumasan sebagai pilihan menu baru kue lebaran. Milanpell Harumasan adalah salah satu produk unggulan KKM 30. Nama Milanpell Harumasan sendiri diambil dari singkatan minyak jelantah pell khas Parumasan yang dipelesetkan menjadi Harumasan. Untuk proses pembuatannya sendiri, kami membutuhkan waktu sekitar 4 Minggu dari belanja bahan, percobaan hingga packaging.

\section{Pembersih Lantai}

Milanpell Harumasan adalah salah satu produk unggulan Nama Milanpell Harumasan sendiri diambil dari singkatan minyak jelantah pell khas Parumasan yang dipelesetkan menjadi Harumasan. Untuk proses pembuata- nnya sendiri, kami 
membutuh- kan waktu sekitar 4 Minggu dari belanja bahan, percobaan hingga packaging. Milanpell harumasan sendiri yaitu, minyak jelantah disaring menggu- nakan penyaring. Hasil penyar- ingan direaksikan dengan larutan $\mathrm{KOH}$ dan arpus.

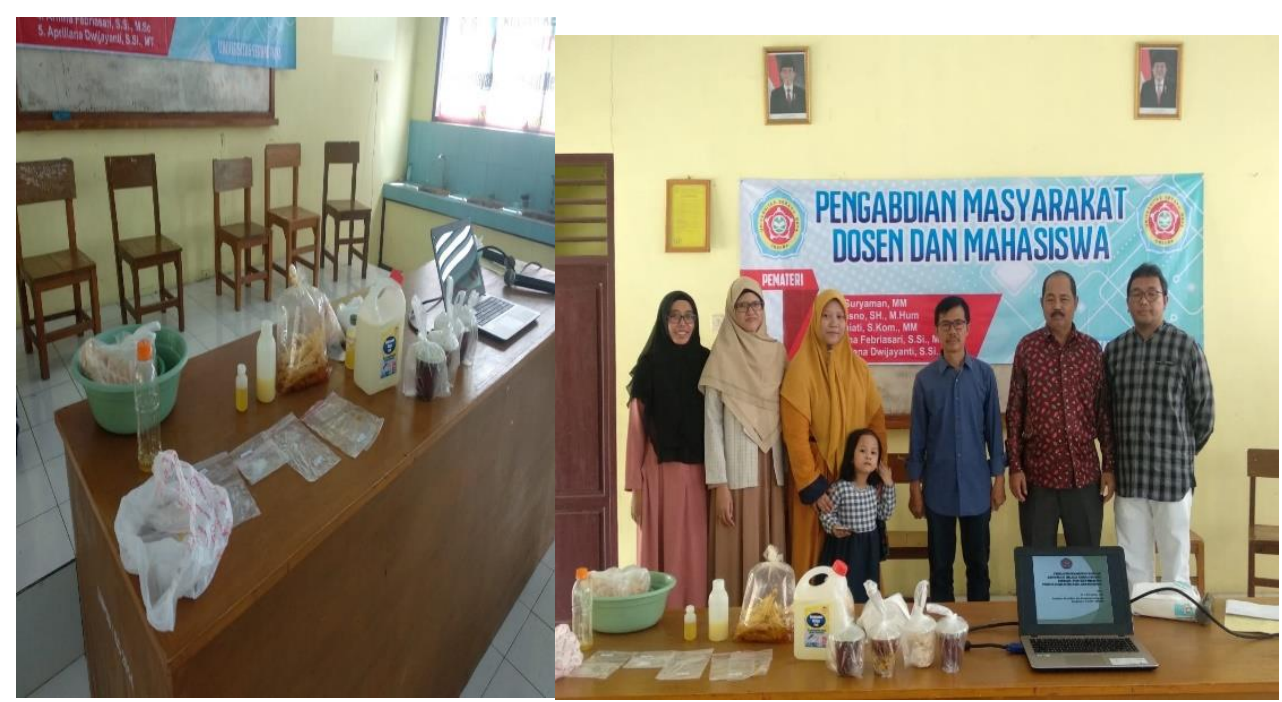

Gambar 1. Pemberdayaan Kelompok Ibu Rumah Tangga Melalui Pembentukan Home Industry Sabun Pencuci Lantai Berbahan Dasar Limbah Minyak Jelantah

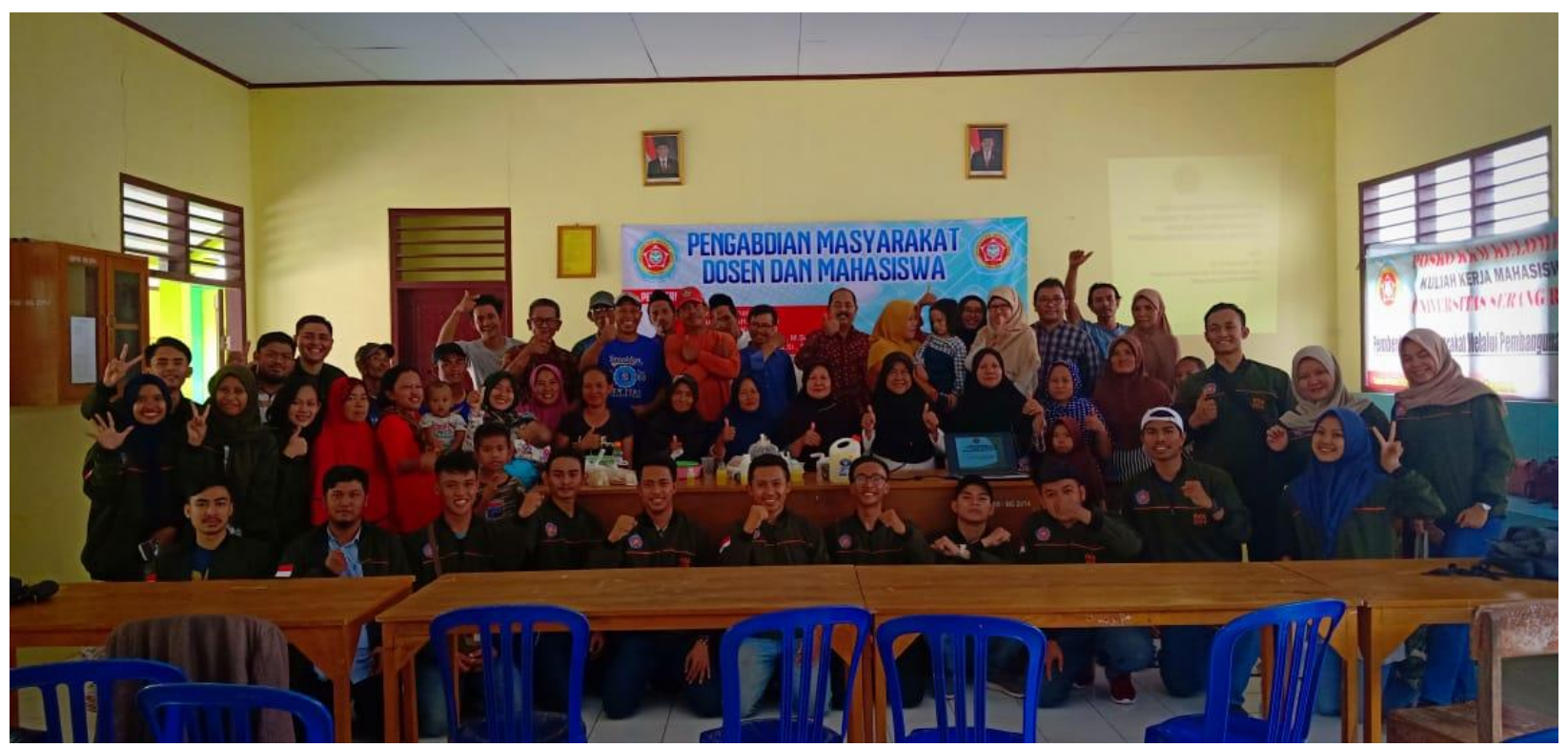

Gambar 2. Sosialisasi Pemberdayaan Kelompok Ibu Rumah Tangga Melalui Pembentukan Home Industry Sabun Pencuci Lantai Berbahan Dasar Limbah Minyak Jelantah 


\section{DAFTAR PUSTAKA}

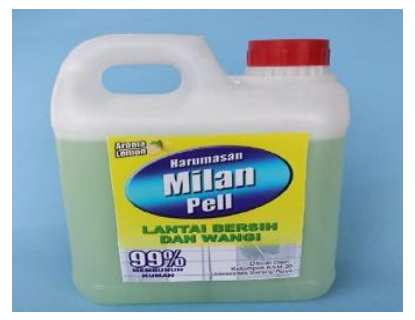

Gambar 3. Hasil Diversifikasi Minyak Jelantah Menjadi Sabun Pencuci Lantai

\section{PENUTUP}

\section{Kesimpulan}

Kegiatan pelatihan menderversifikasi minyak jelantah menjadi produk rumah tangga berjalan dengan lancar, dimana kegiatan ini bertujuan untuk memberikan pengetahuan bagi masyarakat awam mengenai pemanfaatan minyak jelantah, sehingga kesadaran masyarakat tumbuh dan masyarakat membentuk unit unit usaha untuk meningkatkan taraf hidup masyarakat secara mandiri.Kegiatan ini berjalan dengan lancar berkat bantuan dan kerjasama masyarakat.

\section{Saran}

Diharapkan dengan adanya pelatihan Pemberdayaan Kelompok Ibu Rumah Tangga Melalui Pembentukan Home Industry Sabun Pencuci Lantai Berbahan Dasar Limbah Minyak Jelantah terbentuknya unitunit usaha masyarakat dalam Pemberdayaan masyarakat untuk kemandirian perekonomian desa melalui pemanfaatan limbah minyak jelantah menjadi pembersih lantai, kelompok usaha jasa pemanfaatan limbah minyak jelantah menjadi produk rumah tangga yang siap dipasarkan dan memiliki gerai di desa tersebut,dapat meningkatkan daya saing, peningkatan penerapan IPTEK dimasyarakat dan Perbaikan tata nilai masyarakat.

\section{UCAPAN TERIMA KASIH}

Penyusun ucapkan terima kasih kepada semua pihak yang membantu dalam proses pengabdian masyarakat ini sehingga dapat terlaksana dengan baik dan lancar. Terima kasih seluruh Pimpinan Universitas Serang Raya dan Kepada Bapak RT. Serang-Banten
Agustina SE. 2006. Peran Sumber Energi Terbarukan dalam Memenuhi Kebutuhan Energi Nasional.Paper pada Seminar NasionalHemat Energi. Jakarta: 29 Juni 2006.

A.Fuadi Ramdja,Lisa Febriana ,Daniel Krisdianto” Permunian minyak jelantah menggunakan ampas tebu sebagai adsorben" 2010

Dwi Widjanarko,Abdurrahman dan Hadromi” Pengujian Alat pengolah Limbah Minyak Goreng menjadi Biodiesel sebagai bahan bakar alternatif motor diesel"April 2010

Erna Wati Ibnu hajar, Sirril Mufidah," Penurunan Asam lemak bebas pada minyak goreng bekas menngunakan ampas tebu untuk pembuatan sabun" Jurnal Integrasi Proses Vol.6 No.1 Juni 2016

Evi Setiawati, Fatmir Edwar" Teknologi Pengolahan Biodiesel dari minyak goreng bekas dengan teknik Mikrofiltrasi dan transertefikasi sebagai alternatif bahan bakar mesin diesel:Jurnal Riset Industri Vol.VI.No.2 ,2012

Iveba Faustina,Sabrinna Wulandari,Zanetta Auriel" Pemanfaatan Minyak jelantah dan Ekstrak kulit Citrus reticula sebagai bahan pembuatan Sabun “,2014

Masithoh R.E \& Kusumawati Heni, 2016, Pemberdayaan Ibu Rumah Tangga dalam Implementasi Teknologi Pengolahan Sumber Karbohidrat non beras dan penganekaragaman Pangan non terigu untuk mendukung ketahanan pangan, Indonesian Journal of Community Engagement, Volume 02 - No. 01

Nur Asyiah Dalimunthe" Pemanfaatan Minyak Goreng bekas menajdi sabun mandi padat" 2009 